\title{
THEORETICAL-EXPERIMENTAL ANALYSIS OF THE WORKABILITY OF THE Ni50Cr45N0.6 ALLOY
}

In this paper, the results of investigations into, and of the analyses of, the hot deformation behaviour of the Ni50Cr45N0.6 alloy were presented. Compression tests were conducted on a Gleeble 3800 thermo-mechanical simulator within the following temperatures range $850-1200^{\circ} \mathrm{C}$ and within that of the strain rate $1-40 \mathrm{~s}^{-1}$ to the constant true strain of 0.9 , for the purpose of fulfilling the objective of obtaining experimental stress date. Those data were taken advantage of for the purpose of calculating the workability parameters, and that means the efficiency of power dissipation $\eta$, the flow instability $\xi$ and the strain rate sensitivity $m$. The processing maps based upon Murty's criterion were drawn up for the following true strain range: 0.2-0.9, and, subsequently, both processing windows and the flow instability areas were determined. For the alloy being analysed, the most advantageous conditions of metal forming were ascertained within the following range of temperatures: $950-1000^{\circ} \mathrm{C}$, and for that of the strain rate amounting to $10-40 \mathrm{~s}^{-1}$, and that because of (occurring at the temperature of $950^{\circ} \mathrm{C}$ ) the peak of the efficiency of power dissipation parameter $\eta$, amounting to $22 \%$ (in accordance with Murty's criterion). The flow instability areas identified on the processing maps ought to be avoided in metal forming processes. Experimental rolling tests were also conducted.

Keywords: processing maps, processing window, flow instability domain, rolling, microstructure

\section{Introduction}

The $\mathrm{NiCrN}$ alloys from the $\mathrm{NiCr}$ double arrangement are perceived as modern constructional materials, which find their application in constructing machines, devices and installations working in extremely difficult service conditions, and that means at a high temperature, under dynamically (and frequently impact changing) loads, and also in an aggressive corrosion medium. The metal forming of the complicated $\mathrm{NiCrN}$ alloys which are intended to be used as the high-class elements of machines having complex shapes and the high level of resistance properties is significantly restricted by the low level of plasticity and the rapid strengthening of an alloy. In connection with that fact, what is becoming an important issue, is the assessment of the behaviour of an alloy in the course of hot working within the wide range of temperatures, strain rate, and also the true strain. To fulfil the purpose of determining the optimum parameters of the metal forming of the Ni50Cr45N0.6 alloy, and that of attaining the objective of obtaining a product a major feature of which is the best possible functional properties, the systemic approach referred to as Dynamic Material Modelling [1-3] was applied. That approach consists in determining the capacity of a material to undergo plastic deformations, and also the correlations of the constitutive behaviour with microstructural evolution, the flow instability and stability. In this approach, the unit power $(P)$ absorbed by the material in the course of metal forming could be expressed in the following way [2]:

$$
P=\sigma \cdot \dot{\varepsilon}=G+J=\int_{0}^{\dot{\varepsilon}} \sigma_{p} d \dot{\varepsilon}+\int_{0}^{\sigma} \dot{\varepsilon} d \sigma
$$

where: $\sigma$ - the flow stress, MPa, $\dot{\varepsilon}-$ the strain rate, $\mathrm{s}^{-1}, G-$ dissipator content, $J$-dissipator co-content. $J$ co-content [2] as the function of temperature and strain rate at constant true strains is evaluated as:

$$
J=\int_{0}^{\sigma} \dot{\varepsilon} d \sigma=\frac{\sigma \cdot \dot{\varepsilon} \cdot m}{m+1}
$$

where: $m$ - a parameter of the strain rate sensitivity of flow stress which is most often defined by the following equation:

$$
m=\left(\frac{\partial \log \sigma}{\partial \log \dot{\varepsilon}}\right)_{T, \varepsilon}
$$

where: $\varepsilon$ - a constant true strain value, $T$ - temperature, ${ }^{\circ} \mathrm{C}$.

The researchers have proposed various kinds of criteria for the determination of the stability and instability domains in processing map based upon the modelling of the dynamic material behaviour in hot deformation processes. In accordance with Murty's approach [4-7], the strain rate sensitivity parameter $m$ is not a constant one for complex alloy systems. The expression of

\footnotetext{
* AGH UNIVERSITY OF SCIENCE AND TECHNOLOGY, FACULTY OF METALS ENGINEERING AND INDUSTRIAL COMPUTER SCIENCE, AL. A. MICKIEWICZA 30, 30-059 KRAKOW, POLAND ** AGH UNIVERSITY OF SCIENCE AND TECHNOLOGY, FACULTY OF MECHANICAL ENGINEERING AND ROBOTICS, AL. A. MICKIEWICZA 30, 30-059 KRAKOW, POLAND

\# Corresponding author: alukasze@metal.agh.edu.pl
} 
power dissipation efficiency $\eta$ for any type of flow curves can be calculated by means of using a numerical integration procedure and can be expressed as [5]:

$$
\eta=\frac{J}{J_{\max }}=2\left(1-\frac{1}{\sigma \dot{\varepsilon}} \int_{0}^{\dot{\varepsilon}} \sigma d \dot{\varepsilon}\right)
$$

The instability parameter based upon Murty's criterion could be expressed as:

$$
\xi=\frac{2 m}{\eta}-1<0
$$

The power dissipation map is constructed by means of plotting the efficiency of power dissipation parameter $\eta$ at different temperature and strain rates. The variation of the instability parameter $\xi$ with temperature and strain rate created the instability map, which can be superimposed on the power dissipation map to obtain the processing map at constant true strain $[8,9]$. The processing maps make it possible to determine processing windows, a major feature of which is the optimum conditions for the deformation processes. For that very reason, the processing maps are a significant tool supporting the process of designing or modernizing technologies, in particular, in the case of new and difficult to deform alloys, and that means, for example, the NiCr alloys. Wen et al. [7] investigated the hot deformation behaviour of a typical Ni-based superalloy and identified three optimum domains for different forming processes (ingot cogging, conventional die forging and isothermal die forging). Sui et al. [10] developed the processing maps of Inconel 718 at the strains of $0.1,0.3,0.5$ and 0.7 at $950-1150^{\circ} \mathrm{C}$ in the strain rate range of $0.001-100 \mathrm{~s}^{-1}$ and described for forging processes, the temperature range and strain rate range in blank and final production. Wang et al. [11] discussed the hot working windows of $740 \mathrm{H}$ using the processing map and determined VII domains, in which was a potential working window for the extrusion of that alloy. Sun et al. [12] studied the deformation behaviour of In 028 alloy using processing maps, which revealed the domains of fine dynamic recrystallization and one instability domain. Moreover the optimum hot working conditions are suggested. The characteristic of hot deformation of the Inconel (alloy) MA 754 alloy was studied by Somani [13]. It was stated that in this alloy, the dynamic recovery domain occurred instead of dynamic recrystallization domain. In the processes of metal working, a significant parameter, apart from the temperature and strain rate, is strain. In connection with that fact, in some of publications [4,7 and 9], attention is also attracted to the assessment of the influence exerted by the degree of deformation upon hot workability and processing maps, and, in particular, upon changes to the shape, sizes and situation of flow instability areas. Such an approach is determined by the occurrence of the substantial non-homogeneousness of deformation resulting from the character of material flow (material flow behaviour), for example, in the process of impression-die forging. In the case of working on a material having a casting structure, it is of significance to design the appropriate kinematics of material flow and the pattern of deforming, monitoring the size of deformation and the range of temperature, and also strain rate. In addition to that, what is of significance, is the identification of the mechanisms of deformation because some of them are usually situated in the 'unsafe' areas, and may result in a microstructural destruction or non-homogeneousness of varied intensity. Among the 'detrimental' mechanisms of that type, is it possible to enumerate the adiabatic slip bands (resulting in flow localization) or wedge ruptures, resulting from the slip of grain boundaries.

In this paper, upon the basis of the obtained curves of stress-strain from the process of the uniaxial compression of the samples, having a casting structure, the hot deformation behaviour of the Ni50Cr45N0.6 alloy was analysed. The parameters of workability were determined, and also processing maps, were developed in accordance with Murty's criterion at the true strains of $0.9,0.8,0.7,0.5,0.3$ and 0.2 . Processing windows and instability areas were determined. In addition to that, the rolling process was subjected to an assessment in the aspect of the influence exerted by process parameters upon the workability of the investigated alloy.

\section{Material and experiments}

Melting and casting an alloy having the chemical composition determined with the application of the weight method and the thermal conductivity method was presented in Table 1 . The alloy was made at Przedsiębiorstwo Innowacyjne Odlewnictwa (PIO) SPECODLEW Sp. z o.o. (The Innovative Foundry Enterprise SPECODLEW Ltd.) with the application of a classic casting technology [14-17] - pouring liquid metal in the open air into ceramic moulds. The enterprise mentioned above is the only one in the country to have implemented the technology of modifying the alloys of the $\mathrm{NiCr}$ system with the high contents of nitrogen with the application of a special chromium-nitrogen master alloy in an open induction furnace. That technology was developed in collaboration with the specialists from Saint-Petersburg State Polytechnic University (SPTU).

TABLE 1

Chemical composition of Ni50Cr45N0.6 alloy

\begin{tabular}{|c|c|c|c|c|c|c|c|c|c|}
\hline \hline $\mathbf{N i}$ & $\mathbf{C r}$ & $\mathbf{F e}$ & $\mathbf{M n}$ & $\mathbf{M o}$ & $\mathbf{N}$ & $\mathbf{C}$ & $\mathbf{P}$ & $\mathbf{S}$ & $\mathbf{S i}$ \\
\hline 50.34 & 45.44 & 1.09 & 0.059 & 0.003 & 0.6 & 0.012 & 0.003 & 0.007 & 0.18 \\
\hline
\end{tabular}

In Fig. 1, the results of investigating the microstructure of the NiCrN alloy in as-cast condition, conducted with the application of a NEOPHOT 32 metallographical microscope, and also with that of an AXIO observer Z.1 (multiplied twenty times), were presented. The NiCrN alloy in as-cast condition has the microstructure of a $\gamma(\mathrm{Ni})$ type. In large grains, dendritic segregation is observable. On the borders of primary grains, fine unidentified precipitates are observable.

The process of the uniaxial upset forging of the samples was conducted on a Gleeble 3800 thermo-mechanical simulator. Specimens, of $10 \mathrm{~mm}$ diameter and $12 \mathrm{~mm}$ height, machined 


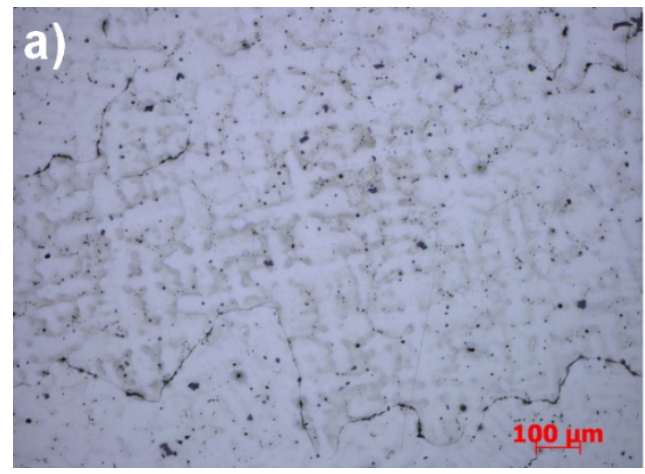

Fig. 1. The microstructure of the $\mathrm{NiCrN}$ alloy

from the initial material, were heated at $2.5^{\circ} \mathrm{C} / \mathrm{s}$ up to the specified temperature. The testing was conducted at the temperatures of $850,900,950,1000,1050,1100,1150$ and $1200^{\circ} \mathrm{C}$, at strain rates of 1,10 and $40 \mathrm{~s}^{-1}$, to the true strain of 0.9 . The specimens were air-cooled to room temperature.

The samples of the investigated alloy obtained from plastometric investigations on a Gleeble simulator were subjected to observation and the assessment of the microstructure on an optical microscope. Every of the samples were cut through parallel to the direction of a strain along the longest chord. Metallographic specimens were etched with the application of a reagent having the following composition: 3 parts of $\mathrm{HCl}-1$ part of $\mathrm{HNO}_{3}$. The time of etching was determined by means of an experiment, and that amounted to between 30 seconds and 5 minutes. The physical verification was conducted in the course of rolling the alloy being investigated on a duo $\varnothing 550$ rolling machine at the Instytut Metalurgii Żelaza in Gliwice. Deformation was set as a single operation, in a flat impression and without restricting the spreading. A number of tests were performed with the application of the different process parameters, paying a particular attention to the lower values of true strain. The material was heated up to the temperature of $990^{\circ} \mathrm{C}$, and, subsequently rolled until obtaining the following sizes of true strain: $0.17,0.25$ and 0.40 . The process parameters were selected in such way that would make them as precisely matching the parameters of the determined processing windows as possible. The charge being analysed

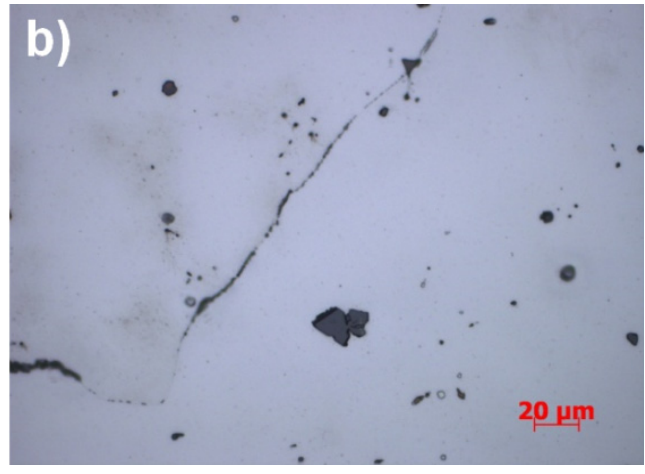

prior to deformation had been subjected to a two-stage thermal treatment. The pattern of the thermal treatment applied for the samples being rolled was presented in Fig. 2. The objective of the two-stage thermal treatment was to remove the dendritic segregation of the structure in as-cast condition. After the rolling process, the forgings were subjected to metallographical examinations.

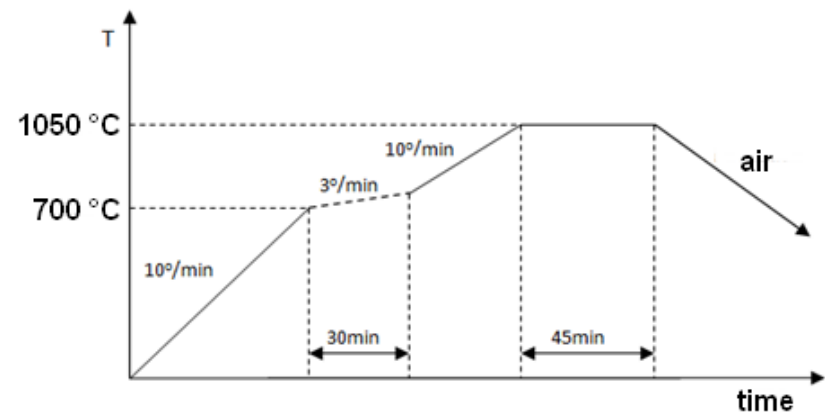

Fig. 2. Pattern of thermal treatment prior to subjecting them to metal forming

\section{Results and discussion}

\subsection{Stress-strain curves}

The stress-strain curves for the investigated temperatures are shown in Fig. 3. The course of the process, in particular, within the following range of temperatures: $800-900^{\circ} \mathrm{C}$, shows
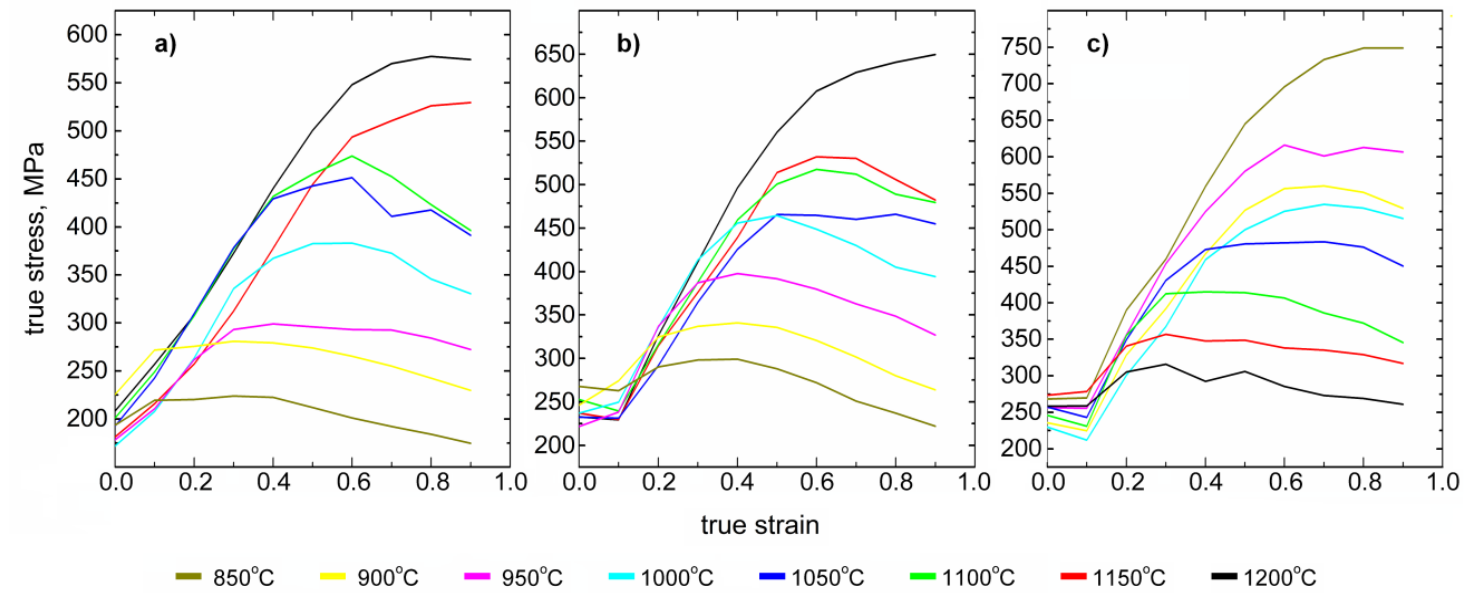

Fig. 3. Stress-strain curves of Ni50Cr45N0.6 alloy at strain rate $1 \mathrm{~s}^{-1}(\mathrm{a}), 10 \mathrm{~s}^{-1}$ (b), and $40 \mathrm{~s}^{-1}$ (c) 
an intensive process of material strengthening with the maximum occurring in the case of strains within the following range of: 0.4-0.6 for the strain rate amounting to $\dot{\varepsilon} \geq 10 \mathrm{~s}^{-1}$. Decrease in flow stress which follows exceeding the maximum value is connected with the relaxation of accumulated internal stresses as the result of the initiation of dynamic recovery on the grain
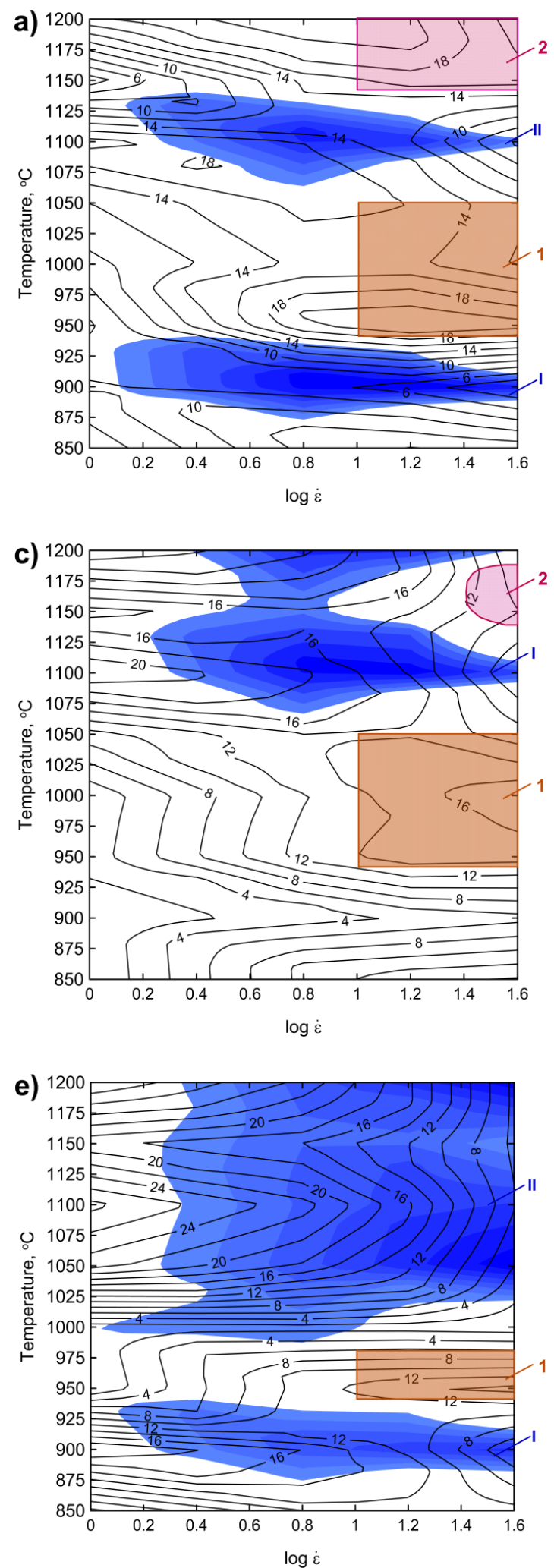

boundaries in the material. Decrease in flow stress is clearly observable simultaneously with increase in the deformation temperature $T=1000-1200^{\circ} \mathrm{C}$. The value of flow stress is also found to correlate with strain rate and, when the value of the strain rate increases, so does the plastic resistance of a material (which happens proportionally).
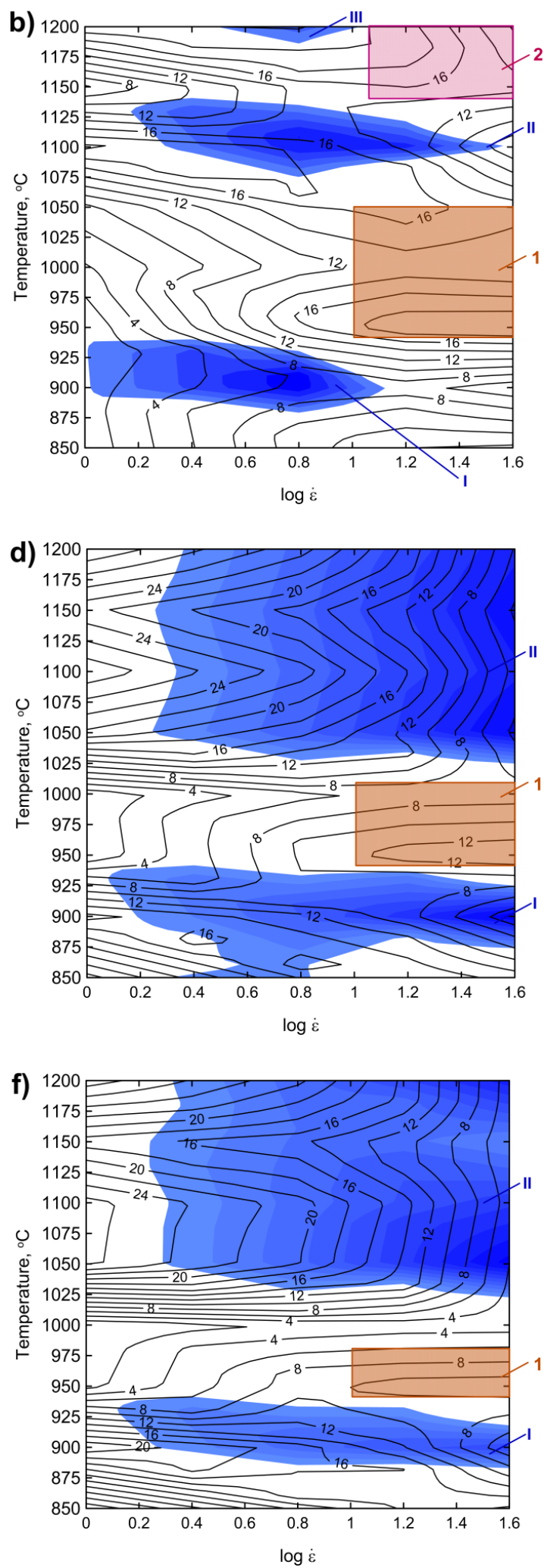

Fig. 4. Processing maps drawn up upon the basis of Murty's criterion for the following true strains of: 0.9 (a), 0.8 (b), 0.7 (c), 0.5 (d), 0.3 (e), 0.2 (f): 1,2 - processing windows, I - III - instability areas 
Upon the basis of the stress-strain curves, the workability parameters: the strain rate sensitivity parameter $m$, the efficiency of power dissipation $\eta$ and the flow instability parameter in accordance with Murty's criterion were determined for the investigated alloy.

Processing maps were plotted for the constant value of true strain amounting to 0.9 , and also for intermediary stages $\varepsilon=0.2-0.8$ and varying temperatures. In Fig. 3, the processing maps drawn up in accordance with Murty's approach were presented.

For the true strain of 0.9 on the processing map (Fig. 4a), two processing windows: 1 (orange colour) and 2 (purple colour), two the instability regimes I and II (blue colour) were defined. Processing window 1 is described by the following parameters: $\eta=12-20 \%, \mathrm{~T}=940-1050^{\circ} \mathrm{C}$, and $\dot{\varepsilon}=10-40 \mathrm{~s}^{-1}$. A changing and complex course of isoclines $\eta(\%)$ may indicate the possibility of the occurrence of certain non-homogeneousness deformation, and also of internal stresses connected with dynamic recrystallization and dynamic recovery. That domain may be recommended for the processes of forge rolling in a sets of grooves with impressions in the system: oval-circle-hexagon, or in the case of nickel-chromium alloys with the addition of nitrogen having the low level of plasticity, a strong deformation resistance and anisotropy in accordance with the elongated hexagon method with concave upper and lower sides in four roll passes: ovalcircle-hexagon elongated-regular hexagon [18]. The preferred relations of the process ought to amount to: $\lambda_{c \min }=1.95$, the degree of deformation $\varepsilon_{I n}=40-60 \%$ for obtaining the uniform distribution of deformation in the sections of forging preforms/ forging, and also changes to the structures and properties. That window may also be recommended for rolling certain elongated forgings having changeable surface until the final form is obtained following the application of set of rolls in accordance with an appropriate roll passes design. In addition to that, within this scope of the processing windows it is possible to forge a wide assortment of drop forgings on a double-acting hammer, a crankoperated press, screw-hydraulic press, and on a screw press with a double-synchronized drive of the screw of an electrical motor.

At the temperature of $T=940-950^{\circ} \mathrm{C}$, and also at that of $T=1000-1050^{\circ} \mathrm{C}$, with the intermediary strain rate of $\dot{\varepsilon}=10-20 \mathrm{~s}^{-1}$, it is possible for a partial and/or complete dynamic recrystallization and dynamic recovery to appear. It is possible as well to arrive at the conclusion that at the temperatures of $T=950-1000^{\circ} \mathrm{C}$ for a high strain rate, there will appear a dynamic recrystallization because the Ni50Cr45N0.6 alloy has a low stacking fault energy (SFE).

Processing window 2 has the shape of a rectangle with the following parameters: $\eta=16-22 \%, T=1140-1200^{\circ} \mathrm{C}$ and $\dot{\varepsilon}=10-40 \mathrm{~s}^{-1}$. The arrangements of the isoclines in processing window 2 may suggest that, at a high temperature, exceeding $1150^{\circ} \mathrm{C}$, and for the high strain rate, exceeding $15 \mathrm{~s}^{-1}$, there may appear a dynamic recrystallization in the material. The isoclines of the efficiency of power dissipation are turned in the direction of ever greater strain rates. The course of them may be the evidence for non-uniform material flow at the tem- perature exceeding $1150^{\circ} \mathrm{C}$, and for the non-uniform condition of stresses. Due to that fact, the non-uniformity of properties is possible in the volume of the forging/preform forging. The window may be recommended for the processes of forge rolling, for forging average drop forgings within the following range of temperatures: $1140-1150^{\circ} \mathrm{C}$, and the large ones, within the following range of temperatures: $1150-1200^{\circ} \mathrm{C}$ on a double-acting hammer, an impact hammer, a horizontal forging machine, and on a mechanical press of the Maxi type.

The flow instability areas I and II, identified on the processing map, may indicate the occurrence of structural defects in the material connected with deformation resistance or the glide of grain boundaries in the case of $\dot{\varepsilon} \ll 10 \mathrm{~s}^{-1}$. In turn, in the case of $\dot{\varepsilon} \gg 10 \mathrm{~s}^{-1}$, there may appear adiabatic slip bands, resulting in flow localization. The above-mentioned mechanisms result from microstructural adverse defects, and also the non-uniformity of deformation having varied intensity. Taking that under consideration, those domains ought to be eliminated from the scope of conducting the hot deformation processes. Processing windows, defined on the processing map for the true strain of 0.8 (Fig. 4b), have an identical process construction like in the case of the true strain of 0.9 . Flow instability areas change their size, shape and situation. For the true strain of 0.8 , three 'unsafe' regimes: I, II and also III, were separated. The flow instability area I has a characteristic shape of a wedge having the following parameters: $T=874-975^{\circ} \mathrm{C}, \dot{\varepsilon}=1-16.5 \mathrm{~s}^{-1}$ and $\eta=1-10 \%$. The course of the isolines is smooth and uniform, which may be the evidence for the structural defects connected only with deformation. The flow instability area II is described by the following parameters: $T=1065-1140^{\circ} \mathrm{C}, \dot{\varepsilon}=3-40 \mathrm{~s}^{-1}$, and $\eta=7-18 \%$. In those areas, it is possible to expect the occurrence of adiabatic slip bands and flow localization. The flow instability area III is a small domain having the following parameters: $T=1178-1200^{\circ} \mathrm{C}$, $\dot{\varepsilon}=5-13.5 \mathrm{~s}^{-1}$ and $\eta=18-21 \%$. That instability is most likely to be connected with deformation resistance, as well as with the slip of grain boundaries in the case of $\dot{\varepsilon} \ll 10 \mathrm{~s}^{-1}$. A major feature of the processing map drawn up for the true strain of 0.7 (Fig. 4c) is the occurrence of only one flow instability area I. On the map showed in Fig. 4c, two processing windows: 1 and 2 were identified. Processing window 1 does not undergo any changes in relation to processing windows 1 for the true strains of 0.9 , and also of 0.8 . In turn, processing window 2 has a clearly reduced surface in reference to processing window 2 for the true strain of 0.8 . That window is described by the following parameters: $T=1140-1190^{\circ} \mathrm{C}, \dot{\varepsilon}=13.5-38 \mathrm{~s}^{-1}$ and $\eta=10-12 \%$. Major features of processing maps for the true strains of $0.5,0.3$, and also of 0.2 , are extensive flow instability areas (marked as I and II), the size of which, together with their shape, and also situation, resulted in eliminating processing window 2. In those areas, one ought to be expecting the defects like the slip of grain boundaries and adiabatic slip bands. For the true strains of $0.5,0.3$, and also 0.2 on the processing map, only one processing window 1 was determined, and the surface of it decreases simultaneously with a decrease in the values of strain (the range of the temperatures of the window is narrowed). 


\subsection{The influence of the deformation conditions upon microstructure}

The examples of the microstructure of samples made of the $\mathrm{NiCrN}$ alloy, deformed on a Gleeble thermo-mechanical simulator, were presented in Fig. 5. Upon the basis of the analysis of the samples microstructure, the non-uniformity of the material deformation was ascertained, and that because of the occurrence of the numerous slip bands and slip lines. In addition to that, what were observed, was the recrystallization processes exceeding $1000^{\circ} \mathrm{C}$. In the zones which have undergone greater deformation recrystallization twins also occurred.

The conducted tests of physical modelling the objective of which was to investigate the possibilities of obtaining larger summary deformations, and a more uniform structure, were performed in reference to the determined processing window 1 . Metallographical investigations on the obtained forgings made it possible to assess the macro- and microstructure following plastic working, and also to reveal the deformations of the structure by means of revealing a change to the shape of primary grains boundaries, material flow lines, slip bands and slip lines. In Fig. 6, the examples of the forging microstructure made of the $\mathrm{NiCrN}$ alloy following a single-operation rolling from a charge in the condition following two-stage thermal treatment were presented.

Upon the basis of the microstructure observation of the forgings obtained in the process of a single-operation rolling from

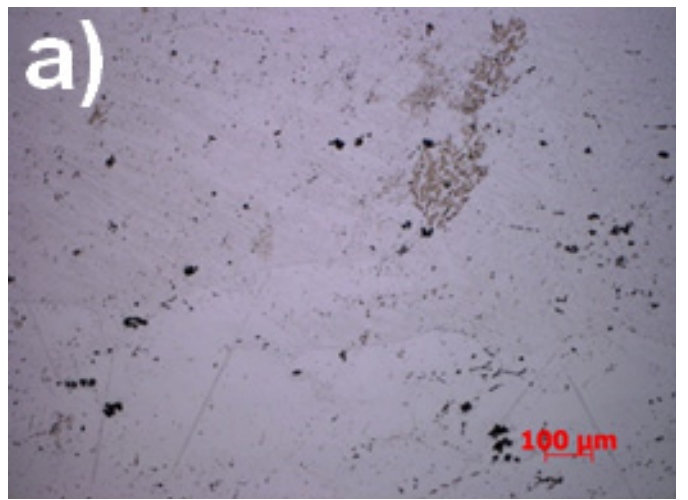

Fig. 5. Microstructure of the $\mathrm{NiCrN}$ alloy following deformation in a Gleeble thermo-mechanical simulator in the following conditions: a) $\mathrm{T}=$ $1000^{\circ} \mathrm{C}, \dot{\varepsilon}=40 \mathrm{~s}^{-1}$, b) $T=1200^{\circ} \mathrm{C}$ and $\dot{\varepsilon}=10 \mathrm{~s}^{-1}$
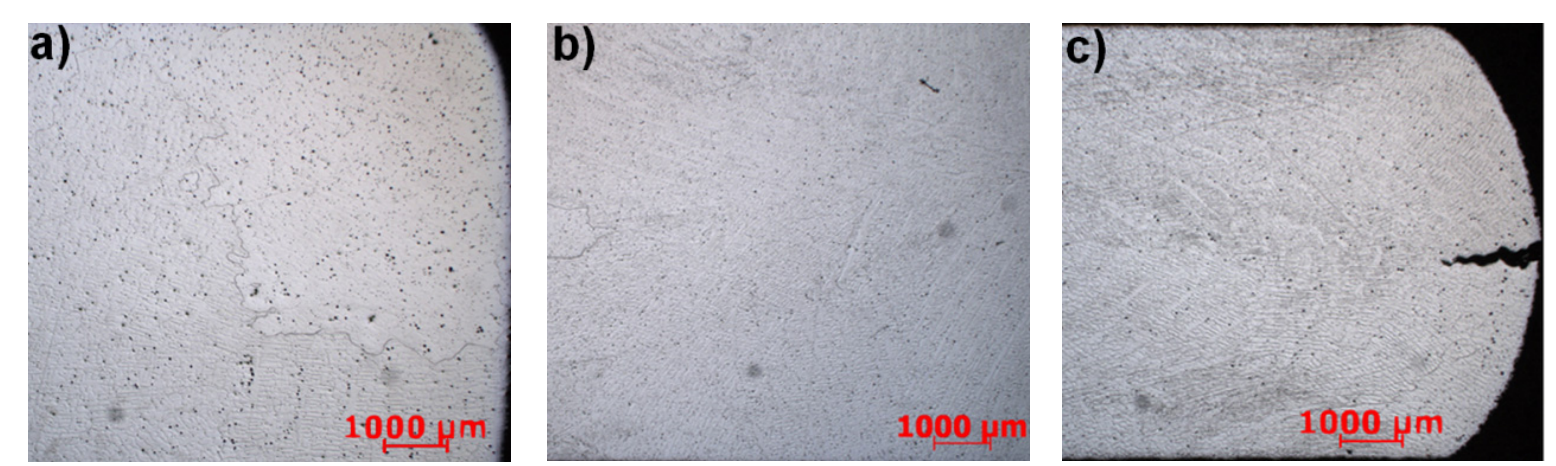

Fig. 6. Macrostructure of the NiCrN alloy from a charge in the condition following a two-stage thermal treatment for the true strain of: a) 0.17 ,

following rolling, primary grains boundaries and slip lines, b) 0.26 , slip bands and slip lines, c) 0.4 , slip bands and slip lines

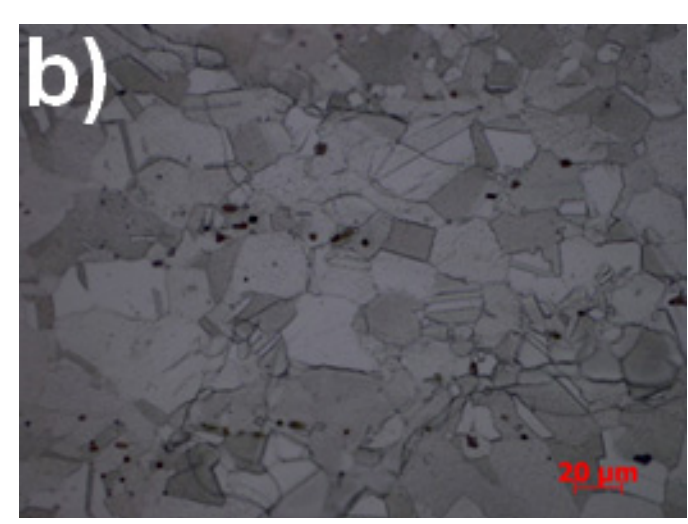

a charge in the condition following two-stage thermal treatment, it was ascertained that the material in the course of rolling is deformed in a non-uniform way. For the sample (Fig. 5a), deformed with a comparatively small rolling reduction, the primary grains boundaries and weakly outlined slip lines were observed. In the lower part of the sample, a cellular distribution of the dislocations may be observed. In addition to that, what was observed, was the occurrence of very-weakly plastically deformed areas in the lateral part of the sample, and in the central one. Fig. 5b presents a sample deformed with a larger rolling reduction. There are already visible slip bands spread uniformly on the entire surface of the sample. A clearly observable strain hardening area in the upper part locks plastic deformation, and results in the relocation of the material from the center to the free edges. The centre of the sample is strongly deformed. Increasing the degree of the rolling reduction results in the formation of new slip bands. In turn, in Fig. 5c, the microstructure of the sample for the greatest deformation was presented. Strongly deformed and strain hardened material is relocated towards the external edges. In the course of rolling on the sample edge, a crack was formed, which may suggest that the upper range of the deformation values for a single-operation process of rolling was achieved. In the upper and lower part of the sample, there are visible slip bands. Throughout the entire volume of the material, there occur numerous areas having a small rolling reduction surrounded by a material more deformed. Such a condition is uniformly spread on the entire cross-section of the sample. 


\section{Conclusions}

The hot deformation behaviour of the Ni55Cr45N0.6 nickel alloy are investigated in temperature range of $850-1200^{\circ} \mathrm{C}$ and strain rate range of $1-40 \mathrm{~s}^{-1}$ at the true strain range of $0.2,0.3$, $0.5,0.7,0.8,0.9$. The processing maps are constructed in accordance with Murty's approach. The processing windows and the instability areas are delineated. The following important conclusions can be drawn:

1. Murty's criterion allowed to determine the characteristic deformation temperature and the effect of forming condition on material flow and microstructure. In addition to that, what was ascertained, was a high level of the sensitivity of the investigated alloy to the thermal conditions of the process. The most advantageous conditions for plastic working in the form of processing windows were determined. The processing windows at the true strain of 0.9 occur in the temperature range of $940-1050^{\circ} \mathrm{C}, 1140-1200^{\circ} \mathrm{C}$ and strain rate range of $10-40 \mathrm{~s}^{-1}$.

2. In the formed processing windows, recommendations relevant to the selection of devices for plastic working in order to fulfill the objective of ensuring uniform deformation were provided.

3. The instability areas were determined, taking under consideration a wide range of strains, which ought to be avoided in the case of the plastic working processes. The size, shape and situation of the flow instability areas are changing simultaneously with changes to strain.

The physical modelling of the deformation of the $\mathrm{NiCrN}$ alloy by means of plastic working were conducted. The process of a single-operation rolling was performed in laboratory conditions on a duo rolling machine in accordance with the determined deformation conditions and with a different true strain. The non-uniform deformation of the material throughout the entire cross-section, or even in one case of damaging the cohesion of material on the edge of a forging, was ascertained. In connection with that fact, it was ascertained that the $\mathrm{NiCrN}$ alloy ought not to be shaped in a single operation with a strain exceeding 0.40 .

\section{Acknowledgments}

The research project was financed by the Polish Ministry of Science and Higher Education (AGH-UST statutory research project no. 11.11.110.292)

\section{REFERENCES}

[1] Y.V.R.K. Prasad, H.L. Gegel, S.M. Doraivelu, J.C. Malas, J.T. Morgan, K.A. Lark, D.R. Barker, Metall. Trans. A 15, 1883-1892 (1984).

[2] Y.V.R.K. Prasad, S. Sasidhara, Hot working guide: A compendium of processing maps, 1997 ASM International, Materials Park OH

[3] Y.V.R.K. Prasad, J. Mater. Eng. Perform. 12, 638-645 (2003).

[4] J. Li, J. Liu, Z. Cui, Mater. Des. 56, 889-897 (2014).

[5] N.S.V.S. Murty, N.B. Rao, Mat. Sci. Eng. A 254, 76-82 (1998).

[6] N.S.V.S. Murty, N.B. Rao, B.P. Kashyap, Int. Mater. Rev. 45, 15-26 (2000).

[7] D. Wen, Y.C. Lin, H. Li, X. Chen, J. Deng, L. Li, Mat. Sci. Eng. A 591, 183-192 (2014).

[8] Y.V.R.K. Prasad, T. Seshacharyulu, Mat. Sci. Eng. A 243, 82-88 (1998).

[9] J. Luo, M. Li, W. Yu, H. Li, Mat. Sci. Eng. A 504, 90-98 (2009).

[10] F.L. Sui, L.X. Xu, L.Q. Chen, X.H. Liu, J. Mater. Process. Tech. 211, 433-440 (2011).

[11] J. Wang, J. Dong, M. Zhang, X. Xie, Mat. Sci. Eng. A 566, 61-70 (2013).

[12] Ch. Sun, G. Liu, Q. Zhang, R. Li, L. Wang, Mat. Sci. Eng. A 595, 92-98 (2014).

[13] M.C. Somani, K. Muraleedharan, N. C. Birla, V. Singh, Y.V.R.K. Prasad, Metall. Mater. Trans. A 25, 1693-1702 (1994).

[14] ASM Handbook, Volume 15 - Casting, 2010 ASM International.

[15] ASM Handbook, Volume 02 - Properties and Selection Nonferrous Alloys and Special Purpose Materials, 1990 ASM International.

[16] N. El-Bagoury, A. Nofal, Mat. Sci. Eng. A 527, 7793-7800 (2010).

[17] L. Nastac, ISIJ Int., 50, (12), 1829-1834 (2010).

[18] A. Świątoniowski (Ed.), Modification of the composition of superalloys based on nickel and chromium by deformation in the rolling process, 2013 AGH: ARBOR FP, Kraków. 